\title{
Patterns of the Diagnosis Prevalence of Psychiatric Disorders in the Population Aged 0-18 Years Based on the Nationwide Insurance Sample Data
}

\author{
Seung Yup Lee ${ }^{1}$ and Geon Ho Bahn ${ }^{2}$ \\ ${ }^{1}$ Happy Medical Clinic, Osan, Korea \\ ${ }^{2}$ Department of Psychiatry, Kyung Hee University School of Medicine, Seoul, Korea
}

Objectives: This study aimed to examine the trend in diagnostic prevalence of psychiatric disorders in children and adolescents.

Methods: Individuals aged 0-18 years were included in the study based on the National Health Insurance Claims Data. To investigate the trends in diagnosis and diagnostic prevalence of psychiatric disorders reflecting the decrease in the birth rate, data were analyzed from 2010 as a reference year to 2015.

Results: The number of patients diagnosed with psychiatric disorder decreased annually, from 23,412 on 2010 to 18,821 on 2015 . The most common disorder was hyperkinetic disorder in male and depressive episode in female. Although there was no significant change in overall diagnostic prevalence rate of psychiatric disorders, age groups $<10$ years and some disorders had significant changes in prevalence rate. This study classified the diagnostic prevalence by age into two unique patterns: group in which the diagnosis rate increases with age and group in which the diagnosis rate peaks at a certain age and then decreases.

Conclusion: Diagnostic prevalence of psychiatric disorders was different according to age and sex. These patterns should be reflected in the formulation of policies related to mental health and in medical practice for pediatric patients. It is urgent to identify how these patterns change in young adults.

Key Words: Psychiatric disorder; Diagnosis prevalence; Adolescents; Childhood; Pattern; Trend.

Received: April 13, 2020 / Revision: June 26, 2020 / Accepted: July 7, 2020

Address for correspondence: Geon Ho Bahn, Department of Psychiatry, Kyung Hee University School of Medicine, 23 Kyungheedae-ro, Dongdaemoon-gu, Seoul 02447, Korea

Tel: +82-2-858-8556, Fax: +82-2-957-1997, E-mail: mompeian@khu.ac.kr

\section{INTRODUCTION}

A considerable number of psychiatric disorders in adults begin to develop in childhood or adolescence [1]. That is, behavioral and emotional problems in the preschool period persist until subsequent periods [2]. A study that followed children aged 9-13 years until 16 years confirmed the continuity of psychiatric disorders [3]. Neurodevelopmental disorders, such as autism spectrum disorder (ASD) or attention-deficit/hyperactivity disorder (ADHD) may also begin in childhood and persist throughout life, further highlighting the need for a survey on the prevalence of psychiatric disorders in children, including preschoolers, and adolescents [4].

The Zürich Epidemiological Study of Child and Adolescent Psychopathology (ZESCAP), which was conducted on 1,964 individuals aged 7-16 years, reported a 6-month men-

This is an Open Access article distributed under the terms of the Creative Commons Attribution Non-Commercial License (https://creativecommons.org/licenses/by-nc/4.0) which permits unrestricted non-commercial use, distribution, and reproduction in any medium, provided the original work is properly cited. tal disorder prevalence of $22.5 \%$ based on parent report or self-report form such as the Child Behavior Checklist and Youth Self-Report [5]. The British Child and Adolescent Mental Health Survey examined the prevalence of mental disorders in 10,438 individuals aged 5-15 years using the Development and Well-Being Assessment and reported a prevalence rate of $9.5 \%$ [6]. In a study on 1,251 individuals aged 7-14 years in Brazil, the prevalence of mental disorders was $12.7 \%$ [7]. As shown here, despite the growing volume of epidemiological study findings on children, the results differ substantially by methodology and target population, and data reflective of the actual clinical setting is limited.

Korea runs a national health insurance system, and care costs claimed by healthcare facilities are reviewed by the Health Insurance Review \& Assessment Service (HIRA). Approximately $97 \%$ of the entire population are enrolled in the National Health Insurance (NHI), and the remaining 2-3\% of the population are beneficiaries of medical aid, whose healthcare costs are paid by the government [8]. The NHI Claims Data (NHICD) is an integration of the data that has 
been reviewed by the HIRA and contains information about patient's general characteristics, diagnosis, history of care, and features of healthcare facility, with $99 \%$ of the data computerized [8]. Therefore, the NHICD is a nationally representative data that feature good objectivity and efficiency.

In the present study, the pediatric patient sample data were obtained from the NHICD for analysis to select common psychiatric disorders in the population aged $<19$ years and examine the trend in the change of diagnostic prevalence and sex- and age-specific differences to complement for the limitations of existing studies on the prevalence of psychiatric disorders in children and adolescents.

\section{METHODS}

\section{Study population}

The study population is the HIRA pediatric patient sample (HIRA-PPS) for 6 years from 2010 to 2015 . The sample size for the HIRA-PPS consisted of $10 \%$ of the entire pediatric population, which was 1,047,802 in 2010 and 932,657 in 2015, with an annual average of 989,016 (Supplementary Table 1 in the online-only Data Supplement). Based on the authors' experience of the previous analysis of 2010 NHICD [9], the present study was set from 2010. As the Korean Standard Classification of Diseases (KCD) [10] underwent a seventh revision in 2016, the study period was set to 2010-2015. The KCD is based on the International Classification of Diseases [11].

The HIRA-PPS consists of statistically sampled, deidentified data from the NHICD and contains information on the claims for cares made for a period of one year from the date of care initiation. The data were established via patient-unit stratified hierarchical sampling according to sex and age groups of all patients who utilized healthcare service during the 1-year period and contained information about the details of their care and prescriptions [8]. These data are provided upon submission of a data request form available on the HIRA website along with a written promise regarding the use of the data and a small fee. However, as the HIRAPPS data is extracted from the insurance claims by year, it is not appropriate for longitudinal studies that follow-up on a group of patients over several years [8].

From individuals who received outpatient or inpatient care from a primary, secondary, or tertiary mental healthcare service institutions, those aged $<19$ years who had been assigned F codes from F00 to F99 for psychiatric disorder in the KCD [10] were extracted for analysis. To enhance the diagnostic accuracy, patients diagnosed with a psychiatric disorder exclusively by psychiatrists were included in the analysis. As previous studies that utilized the NHICD $[9,12]$ set their study population to those aged $<19$ years, the study population was also set to those aged $<19$ years to enable comparison with the authors' previous studies. Both the main diagnosis and subdiagnosis were included, and the diagnoses were classified by the KCD [10].

\section{Methods}

To compare with the authors' previous studies that utilized the NHICD [9,12], the study population was divided into 3-year units to analyze the prevalence of $\mathrm{F}$ code by year, age, and sex. The year 2010, which is the first year of data for the study population, was set as the reference point to compare yearly trends. This study was approved by the Institutional Review Board of Kyunghee University Hospital (KMC IRB 2017-07-029).

\section{Statistical analysis}

The changes in the prevalence of psychiatric disorders from 2010 to 2015 by age, sex, and insurance type were examined based on the rate of increase or decrease in the annual average and significance of the trends using a trend test. The prevalence rate was converted to a percentage of the $\mathrm{F}$ code diagnosed by psychiatrists per 1,000 population included in each group as designated by Statistics Korea.

In addition, for $F$ codes with a prevalence rate of $\geq 1 \%$, yearly changes in their prevalence by sex were analyzed using a trend test.

The data were analyzed using the SAS 9.4 software (SAS Institute Inc., Cary, NC, USA), R 3.5.1 (https://cran.r-project.org), and yearly and sex-specific diagnostic prevalence rates were graphed using "gridExtra," "ggplot2," "plyr," and "gtools" packages. The trend test was performed by applying the "lm" package. The statistical significance was set at 0.05 for all analyses.

\section{RESULTS}

Of patients aged $<19$ years who received outpatient or inpatient care in psychiatric healthcare institutions as shown in the HIRA-PPS data, an annual average of 22,150 patients, with 23,412 in 2010 and 18,821 in 2015, were diagnosed with psychiatric disorders (F00-99) (Supplementary Table 2 in the online-only Data Supplement).

There were 14 psychiatric disorders with a diagnostic prevalence of $\geq 1 \%$ in the study population, written in the order of the following codes: bipolar affective disorder (F31); depressive episode (F32); other anxiety disorders (F41); reaction to stress and adjustment disorders (F43); somatoform disorders (F45); other neurotic disorders (F48); mental retardation, mild (F70); specific developmental disorders of speech and language (F80); pervasive developmental disor- 
Table 1. High ranked psychiatric disorders as standard of diagnosis prevalence in the year 2010

\begin{tabular}{|c|c|c|c|c|c|c|c|}
\hline \multirow[b]{2}{*}{ F-code } & \multirow[b]{2}{*}{ Diagnosis } & \multicolumn{2}{|c|}{ Male } & \multicolumn{2}{|c|}{ Female } & \multicolumn{2}{|c|}{ Total } \\
\hline & & $\begin{array}{l}\text { Diagnosis } \\
\text { prevalence }\end{array}$ & $\begin{array}{l}\text { Weighted \%o } \\
\text { of population }\end{array}$ & $\begin{array}{l}\text { Diagnosis } \\
\text { prevalence }\end{array}$ & $\begin{array}{l}\text { Weighted \%o } \\
\text { of population }\end{array}$ & $\begin{array}{l}\text { Diagnosis } \\
\text { prevalence }\end{array}$ & $\begin{array}{l}\text { Weighted \%o } \\
\text { of population }\end{array}$ \\
\hline F90 & Hyperkinetic disorders & 6525 & 11.46 & 1797 & 3.46 & 8322 & 7.65 \\
\hline F32 & Depressive episode & 2148 & 3.77 & 1810 & 3.49 & 3958 & 3.64 \\
\hline F41 & Other anxiety disorders & 1872 & 3.29 & 1779 & 3.43 & 3651 & 3.36 \\
\hline F43 & $\begin{array}{l}\text { Reaction to severe stress, } \\
\text { and adjustment disorders }\end{array}$ & 1052 & 1.85 & 1104 & 2.13 & 2156 & 1.98 \\
\hline F95 & Tic disorders & 1723 & 3.03 & 351 & 0.68 & 2074 & 1.91 \\
\hline F93 & $\begin{array}{l}\text { Emotional disorders with onset } \\
\text { specific to childhood }\end{array}$ & 1209 & 2.12 & 746 & 1.44 & 1955 & 1.80 \\
\hline F45 & Somatoform disorders & 796 & 1.40 & 918 & 1.77 & 1714 & 1.58 \\
\hline F98 & $\begin{array}{l}\text { Other behavioural and emotional } \\
\text { disorders with onset usually occurring } \\
\text { in childhood and adolescence }\end{array}$ & 817 & 1.44 & 472 & 0.91 & 1289 & 1.18 \\
\hline F80 & $\begin{array}{l}\text { Specific developmental disorders of } \\
\text { speech and language }\end{array}$ & 908 & 1.60 & 264 & 0.51 & 1172 & 1.08 \\
\hline F84 & Pervasive developmental disorders & 948 & 1.67 & 188 & 0.36 & 1136 & 1.04 \\
\hline F70 & Mild mental retardation & 715 & 1.26 & 340 & 0.66 & 1055 & 0.97 \\
\hline F48 & Other neurotic disorders & 430 & 0.76 & 512 & 0.99 & 942 & 0.87 \\
\hline F91 & Conduct disorders & 685 & 1.20 & 250 & 0.48 & 935 & 0.86 \\
\hline F31 & Bipolar affective disorder & 374 & 0.66 & 229 & 0.44 & 603 & 0.55 \\
\hline
\end{tabular}

der (F84); hyperkinetic disorders (F90); conduct disorders (F91); emotional disorders with onset specific to childhood (F93); tic disorders (F95); and other behavioral and emotional disorders with onset usually occurring in childhood and adolescence (F98) (Supplementary Table 3 in the online-only Data Supplement). In the reference year of 2010, the highest diagnostic prevalence for the entire subjects including both sexes was observed in F90, followed by F32, F41, F43, and F95 (Table 1). The diagnostic prevalence distribution differed between the two sexes, with the most common diagnosis being F90, followed by F32, F41, F95, and F93, in male but F32, followed by F90, F41, F43, and F45, in female.

While the number of individuals diagnosed with a psychiatric disorder declined over the years, the percentage of diagnosis in the entire population did not change statistically significantly (Table 2). However, this rate was on a significant decline only in the female medical aid beneficiary group. By age, there was a significant declining trend in the $\leq 9$ years group (Table 2). Regarding changes in the annual diagnostic rates, there was a significant increasing trend for codes F31, F32, F41, F80, F84, and F95 in both male and female (Table 3). In male, there was a significant increasing trend also for code F91, but the diagnostic rate for F48 and F98 significantly decreased. In female, the diagnostic rate for F93 and F98 significantly decreased. When compared between sexes, the increasing trend for F31 and F84 was stronger in male than in female.
By age group, there was a fixed, unique pattern for each psychiatric disorder (Figs. 1 and 2). Two different patterns were detected: 1) the diagnosis rate increases with age for F31, F32, F41, F43, F45, and F48 in both sexes; 2) the diagnosis rate peaks at a certain age and then decreases, which in turn can be subdivided into three subgroups: 2-1) peaks at 4-6 years and decreases rapidly for F80, F84, and F98; 2-2) peaks at 7-9 years and decreases for F70, F90, F93, and F95; and 2-3) peaks at 13-15 years for F91. Exceptionally, for F98, the diagnosis rate peaks at 4-6 years or 7-9 years in male.

\section{DISCUSSION}

The results of this study showed that there were no significant changes in the diagnostic prevalence for psychiatric disorders. Particularly, the diagnostic prevalence of hyperactivity disorder did not change significantly. This is contradictory to the argument that the diagnosis of ADHD is sharply increasing annually and that medications are misused and abused in children [13]. This is also in contrast with the result of a study on the long-term incidence rate of ADHD that the number of diagnoses is continuously increasing [14]. In this study, the authors observed that the diagnosis rate has significantly decreased in the $\leq 9$ years group annually. In fact, the ADHD diagnostic rate or drug 
therapy rate in Korea is markedly lower than the anticipated prevalence [15], so a multilateral analysis is needed for the low number of diagnosis and therapeutic exposure. Certain pediatric neurodevelopmental disorders, such as ASD and ADHD, show early onset, which highlights the pressing need to analyze the structural problem underlying the absence of change in the diagnostic rate, as a delay of early diagnosis raises concerns for exacerbation of symptoms and secondary complications [16].
In this study, the diagnosis of bipolar affective disorder, depressive episode, other anxiety disorders, specific developmental disorders of speech and language, pervasive developmental disorder, and tic disorder increased over the years in both male and female. While the increase in the diagnostic rate of bipolar affective disorder may be reflective of an actual increase in the diagnosis, it may also be associated with the change in the insurance payout criteria pertaining to the prescription of psychotropics used for ADHD or ASD $[8,16]$.

Table 2. Trend analysis of psychiatric diagnosis prevalence according to age and years during 2010-2015

\begin{tabular}{|c|c|c|c|c|c|c|c|c|c|}
\hline \multirow{2}{*}{ Types } & \multicolumn{6}{|c|}{ Prevalence (the number of people per 1000) } & \multicolumn{3}{|c|}{ Trend test } \\
\hline & 2010 & 2011 & 2012 & 2013 & 2014 & 2015 & Trend* & SE & p-value \\
\hline \multicolumn{10}{|l|}{ Total } \\
\hline Male & 25.38 & 26.58 & 28.34 & 26.62 & 24.62 & 23.42 & -0.497 & 0.389 & 0.2709 \\
\hline Female & 17.27 & 17.08 & 18.86 & 16.93 & 15.99 & 15.37 & -0.420 & 0.242 & 0.1574 \\
\hline Total & 21.51 & 22.04 & 23.80 & 21.96 & 20.46 & 19.54 & -0.470 & 0.312 & 0.2072 \\
\hline \multicolumn{10}{|c|}{ Medical insurance } \\
\hline Male & 23.62 & 24.83 & 26.48 & 24.88 & 22.88 & 21.68 & -0.490 & 0.381 & 0.2677 \\
\hline Female & 15.57 & 15.47 & 17.23 & 15.47 & 14.53 & 13.95 & -0.362 & 0.238 & 0.2028 \\
\hline Subtotal & 19.78 & 20.36 & 22.05 & 20.36 & 18.86 & 17.95 & -0.438 & 0.307 & 0.2263 \\
\hline \multicolumn{10}{|l|}{ Medical aid } \\
\hline Male & 1.76 & 1.75 & 1.86 & 1.74 & 1.74 & 1.74 & -0.007 & 0.012 & 0.6036 \\
\hline Female & 1.71 & 1.61 & 1.63 & 1.46 & 1.46 & 1.42 & -0.059 & 0.010 & 0.0047 \\
\hline Subtotal & 1.73 & 1.68 & 1.75 & 1.61 & 1.61 & 1.58 & -0.032 & 0.010 & 0.0374 \\
\hline \multicolumn{10}{|l|}{$0-3$ years } \\
\hline Male & 6.32 & 7.23 & 6.27 & 6.35 & 6.17 & 5.25 & -0.242 & 0.117 & 0.1081 \\
\hline Female & 3.72 & 3.98 & 3.34 & 3.01 & 2.90 & 2.69 & -0.249 & 0.049 & 0.0069 \\
\hline Subtotal & 5.06 & 5.65 & 4.85 & 4.72 & 4.58 & 4.00 & -0.247 & 0.078 & 0.0336 \\
\hline \multicolumn{10}{|l|}{$4-6$ years } \\
\hline Male & 19.69 & 19.67 & 19.12 & 19.15 & 17.69 & 17.56 & -0.473 & 0.095 & 0.0076 \\
\hline Female & 10.73 & 10.33 & 9.93 & 8.88 & 7.81 & 7.54 & -0.702 & 0.068 & 0.0005 \\
\hline Subtotal & 15.37 & 15.16 & 14.67 & 14.17 & 12.90 & 12.70 & -0.590 & 0.072 & 0.0012 \\
\hline \multicolumn{10}{|l|}{$7-9$ years } \\
\hline Male & 34.49 & 35.44 & 38.46 & 34.24 & 30.02 & 27.97 & -1.516 & 0.679 & 0.0894 \\
\hline Female & 15.45 & 14.86 & 14.83 & 13.03 & 11.72 & 10.52 & -1.024 & 0.134 & 0.0016 \\
\hline Subtotal & 25.37 & 25.57 & 27.09 & 24.02 & 21.17 & 19.51 & -1.301 & 0.416 & 0.0353 \\
\hline \multicolumn{10}{|l|}{$10-12$ years } \\
\hline Male & 31.27 & 33.17 & 35.80 & 33.45 & 30.59 & 29.54 & -0.535 & 0.547 & 0.3830 \\
\hline Female & 13.98 & 14.43 & 16.62 & 14.24 & 13.37 & 12.78 & -0.331 & 0.310 & 0.3462 \\
\hline Subtotal & 23.02 & 24.22 & 26.63 & 24.25 & 22.33 & 21.47 & -0.451 & 0.429 & 0.3524 \\
\hline \multicolumn{10}{|l|}{$13-15$ years } \\
\hline Male & 30.16 & 32.17 & 36.12 & 33.51 & 30.88 & 27.45 & -0.572 & 0.741 & 0.4833 \\
\hline Female & 23.07 & 22.08 & 26.73 & 23.16 & 21.56 & 20.98 & -0.445 & 0.499 & 0.4231 \\
\hline Subtotal & 26.79 & 27.36 & 31.63 & 28.57 & 26.42 & 24.36 & -0.515 & 0.599 & 0.4380 \\
\hline \multicolumn{10}{|l|}{$16-18$ years } \\
\hline Male & 28.69 & 30.38 & 33.66 & 33.07 & 32.14 & 32.94 & 0.742 & 0.349 & 0.1008 \\
\hline Female & 32.27 & 32.34 & 36.36 & 34.19 & 33.79 & 33.62 & 0.255 & 0.379 & 0.5376 \\
\hline Subtotal & 30.36 & 31.30 & 34.93 & 33.60 & 32.93 & 33.27 & 0.517 & 0.356 & 0.2203 \\
\hline
\end{tabular}




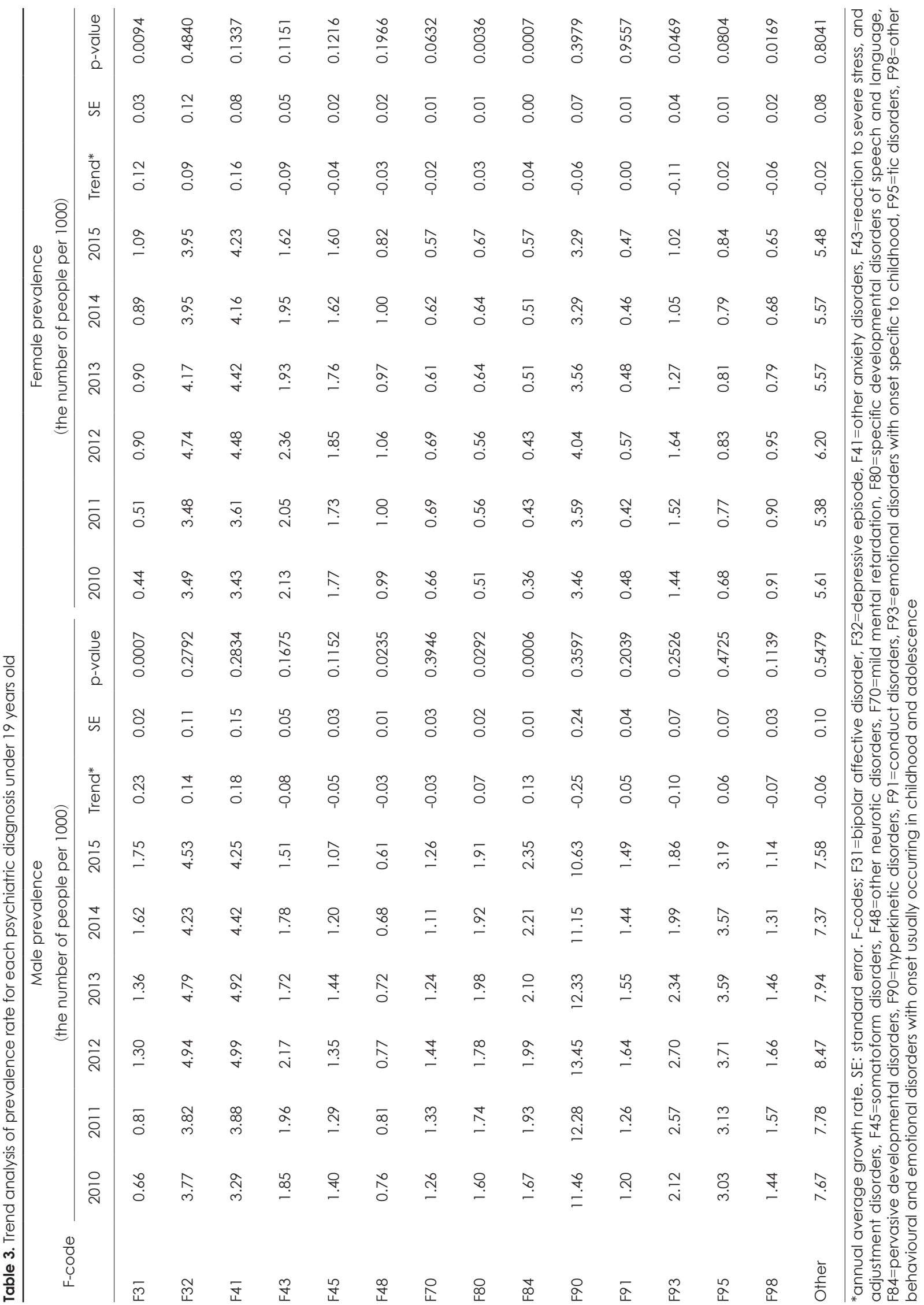


The analysis of Korea's NHICD from 2008 to 2015 showed that the annual diagnostic rate of ASD increased from 5.04 (per 100,000 individuals) to 10.97 [16]. In the US National Health Interview Survey, the prevalence of ASD increased from $1.1 \%$ in 2009 to $2.5 \%$ in 2017 [4]. The reasons for the increasing ASD diagnostic rate may include the broader diagnostic criteria for ASD than pervasive developmental disorder, increased awareness of the disease among experts and

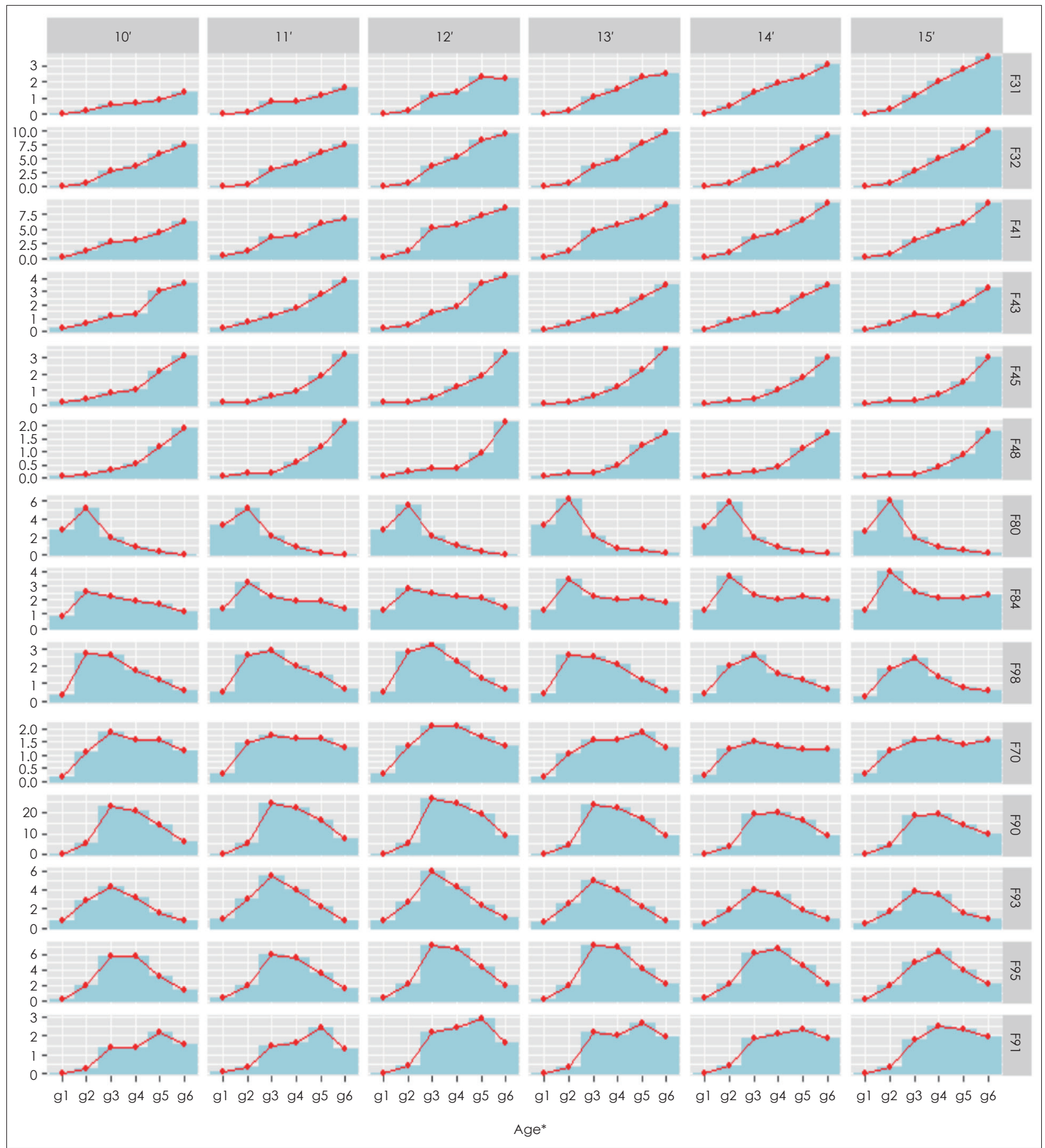

Fig. 1. Characteristics in the diagnosis prevalence of psychiatric disorders in males according to age during 2010-2015. *Age; $\mathrm{gl}=0-3$ years old, $\mathrm{g} 2=4-6$ years old, $\mathrm{g} 3=7-9$ years old, $\mathrm{g} 4=10-12$ years old, $\mathrm{g} 5=13-15$ years old, $\mathrm{g} 6=16-18$ years old. $\mathrm{F}$-codes; F31=bipolar affective disorder, F32=depressive episode, F41=other anxiety disorders, F43=reaction to severe stress, and adjustment disorders, F45=somatoform disorders, F48=other neurotic disorders, F70=mild mental retardation, F80=specific developmental disorders of speech and language, F84=pervasive developmental disorders, F90=hyperkinetic disorders, F91=conduct disorders, F93=emotional disorders with onset specific to childhood, F95=tic disorders, F98=other behavioural and emotional disorders with onset usually occurring in childhood and adolescence. 
parents, and increased development of early intervention services for these children [4]. In Korea, the reason for the increase in the prevalence of specific developmental disorders of speech and language may be attributable to the vouchers for families of children with disability [17]. Thus, this may be due to the launching of vouchers for developmental rehabilitation service in February 2009 and vouchers for speech-language therapy service in August 2010 [17]. Be-

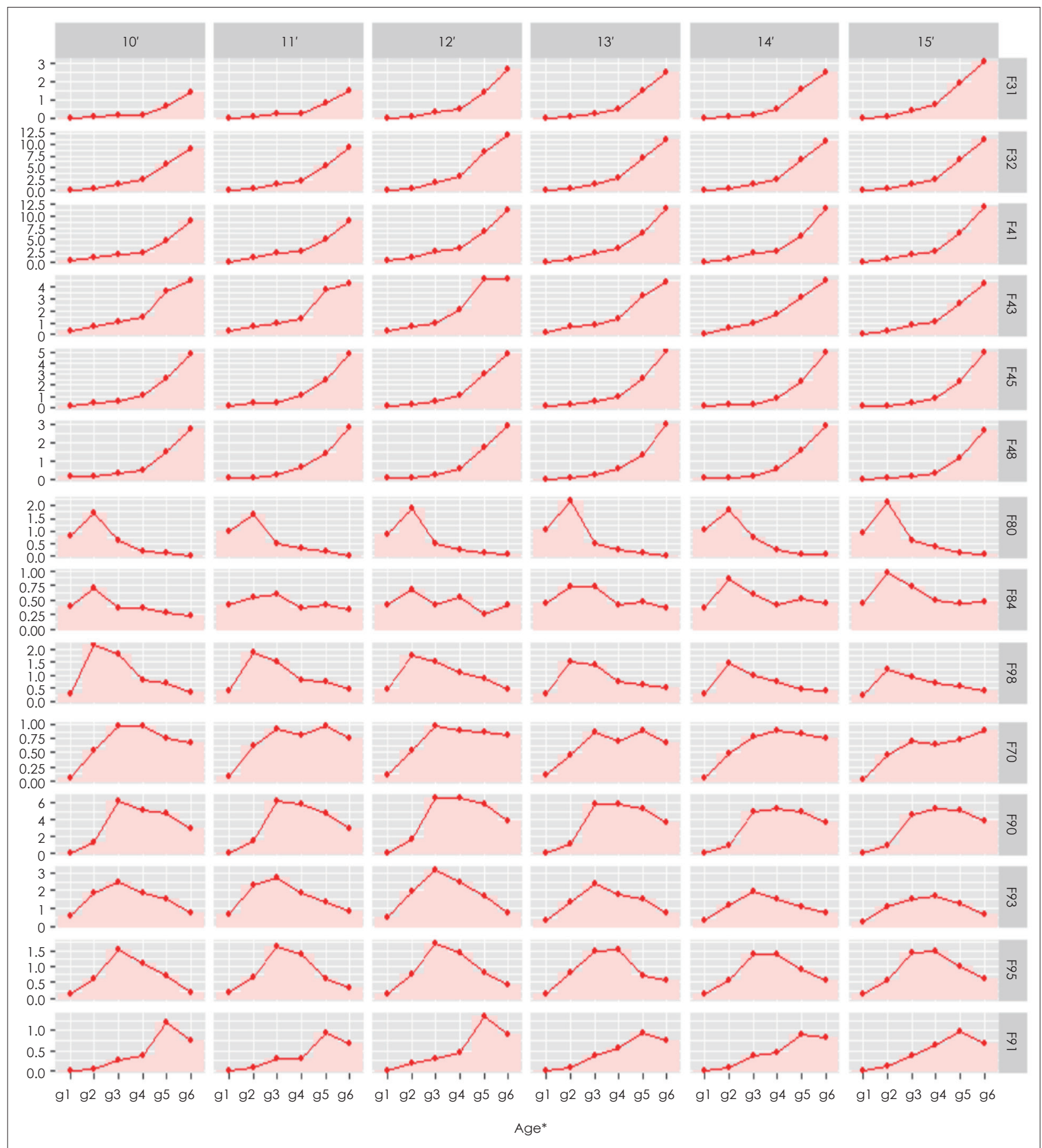

Fig. 2. Characteristics in the diagnosis prevalence of psychiatric disorders in females according to age during 2010-2015. *Age; $\mathrm{gl}=0-3$ years old, $\mathrm{g} 2=4-6$ years old, $\mathrm{g} 3=7-9$ years old, $\mathrm{g} 4=10-12$ years old, $\mathrm{g} 5=13-15$ years old, $\mathrm{g} 6=16-18$ years old. $\mathrm{F}-\mathrm{codes}$; F31=bipolar affective disorder, F32=depressive episode, F41=other anxiety disorders, F43=reaction to severe stress, and adjustment disorders, F45=somatoform disorders, F48=other neurotic disorders, F70=mild mental retardation, F80=specific developmental disorders of speech and language, F84=pervasive developmental disorders, F90=hyperkinetic disorders, F91=conduct disorders, F93=emotional disorders with onset specific to childhood, F95=tic disorders, F98=other behavioural and emotional disorders with onset usually occurring in childhood and adolescence. 
cause people consider the diagnosis of a mental disorder as a stigma, there are cases in which parents seek treatment under the code as R62, delayed milestone, and R47, speech disturbance not elsewhere classified, which increases the possibility that the actual prevalence of specific developmental disorders of speech and language and pervasive developmental disorder may be higher [17].

A 2005 Korean pediatric prevalence report for psychiatric disorders [18] showed the order of prevalence as ADHD, tic disorders, and anxiety disorders, but a recent study reported that other anxiety disorders and depressive episodes had the highest diagnostic rate in late adolescence and early female adulthood [19]. In a study on the prevalence of pediatric mental disorders in Taiwan, which runs a national health insurance system similar to that of Korea, the lifetime prevalence was the highest for anxiety disorder at $15.2 \%$, followed by ADHD, sleep disorder, and tic disorder [20]. In the present study, the increasing trends of bipolar affective disorder and pervasive developmental disorder were stronger in male than in female. While the result for pervasive developmental disorder is similar to that observed in previous studies, the result that the increasing trend in bipolar affective disorder was stronger in male than in female differs from the findings of a community-based study, where most trends were consistent between male and female [3]. As previously mentioned, this may be related to the increasing use of psychotropics prescribed to patients with ASD as a result of an increase in the diagnostic rate of ASD [9].

The authors identified a characteristic pattern in the distribution of diagnostic prevalence by age. There were two patterns: 1) continuous increase in diagnostic rate with age and 2) peaks at a certain age and decrease. First, the diagnosis rate increases continually with advancing age in bipolar affective disorder (F31), depressive episode (F32), other anxiety disorders (F41), reaction to stress and adjustment disorder (F43), and somatoform disorders (F45). In the present study, depressive episode increases with increasing age regardless of sex, particularly after the age of 13 years. In the Quebec Child Mental Health Survey (QCMHS) conducted on children and adolescents aged 6-14 years, depressive disorder was more prevalent in younger children than in adolescents in male and was about 6.6 times more prevalent in female adolescents compared to male adolescents [21]. Similar to our findings, a Korean study that assessed depressive symptoms in 2,203 individuals observed that depressive symptoms increased in the high school period compared to the middle school period [22].

In this study, other anxiety disorders were more common among female and increased with increasing age in both sexes. It was more common in female than in male and those aged 6-8 years than those aged 12-14 years from QCMHS [21]. However, unlike the present study, the said study included separation anxiety disorder and simple phobia, which do not fall under other anxiety disorders (code F41). A follow-up of children aged 9-13 years until the age of 16 years revealed that the prevalence of depressive disorder and social phobia increased among female adolescents [3]. The prevalence of anxiety disorder among preschool children aged 2-5 years was $<1 \%$, with $0.5 \%$ for separation anxiety disorder and $0.6 \%$ for simple phobia [23]. The lower prevalence in this group compared to older children may be due to the difficulty of identifying internalizing symptoms in young childhood.

The prevalence of specific developmental disorders of speech and language (F80), pervasive developmental disorder (F84), and other behavioral and emotional disorders with onset usually occurring in childhood and adolescence (F98) peaks in 4-6 years group, after which it continues to decline. Following early diagnosis, patients with these disorders are likely to receive intervention under the diagnosis of different mental problems with $\mathrm{R}$ or $\mathrm{Z}$ codes or due to coexistent symptoms after the age of 6 years [17]. This is because when patients with ASD are prescribed medications due to behavioral problems during growth, such as self-mutilation, impulsivity, and aggression, the diagnosis of psychoticismrelated disorders must be provided in place of ASD due to the current health insurance regulations [9]. The reason for the decline in the prevalence after 4-6 years may be that the chief discomfort from specific developmental disorders of speech and language shifts from language to problems in social functioning and social relationships in adulthood [1]. As rehabilitation service utilization among children aged $<19$ years with disabilities is increasing annually from $56.0 \%$ in 2011 to $62.5 \%$ in 2014 and $69.4 \%$ in 2017 in Korea, it is possible that this pediatric patient population may receive service from paramedical specialists, which is not covered by national health insurance, once they pass the preschool period [17]. The reason for the decrease in the diagnostic rate of other behavioral and emotional disorders with onset usually occurring in childhood and adolescence with advancing age may be attributable to possible improvement of problems in young childhood in later ages, possibility that the patient did not seek medical care even with persistent problems, and possibility that the patient was rediagnosed with another psychiatric disorder later in life as the problems became clearer [12].

The prevalence rate for mental retardation (F70), hyperactivity disorder (F90), emotional disorder with onset specific to childhood (F93), and tic disorder (F95) spikes in a certain age group and then declines. Mental retardation in- 
creases with advancing age until reaching a plateau, after which it begins to decline. A meta-analysis of the prevalence of mental retardation reported that mental retardation becomes less prevalent among adults compared to children and adolescents, because, even though children and adolescents had been burdened with school, adults have left school and thus show a decline in academic pressure and prevalence of mental retardation [24]. Although this might be a result reflecting the loss of the need to diagnose mental retardation, as patients with mild mental retardation show mild improvements in adaptive functions through early diagnosis and intervention, it may also be a result of discontinuation of treatment following diagnosis [12]. In the present study, the diagnostic rate of hyperactivity disorder sharply increases at the age of 7-9 years and then begins to decline slowly. A study that observed changes from elementary school period to adolescence reported that the prevalence of ADHD, separation anxiety disorder, enuresis, encopresis, and tic disorder had a downturn from the age of 12 years [3]. A study that investigated diagnostic rates in the period between ages 3 and 6 years found that the 3 -month prevalence of ADHD significantly increased from 2.4\% among children aged 3 years to $5.4 \%$ among children aged 6 years [25]. As the period of school entry is marked by escalated social and academic needs and needs for behavioral control, symptoms are more clearly identified.

Lastly, conduct disorder (F91) in childhood is known to have an adverse effect on the development of internalization symptoms in adulthood [26]; however, it might not fit well in the clinical practice. It also differs culturally and by country. The diagnostic rate of conduct disorder in this study steeply increased at the age of 13-15 years and declined afterward. In the previous studies that analyzed HIRA-NPS of the year 2011, the diagnostic rates of F91 were $1.9 \%$ among the $0-18$-year-old population [12] and dropped to $0.09 \%$ among the $19-30$-year-old population [19]. Estimates of point prevalence rate of conduct disorder from 5-15 years in the UK [6] and from youths aged 11-17 years in the USA [27] were $1.47 \%$ and $3.32 \%$, respectively. Interestingly, the diagnostic prevalence of conduct disorder abruptly increased from $1.25 \%$ in the 11-12-year-old population to $3.31 \%$ in the $13-15$-year-old population in the UK study [6]. The 12-month first incidence rate of conduct disorder was $1.88 \%$ in a community study with youths aged 11-17 years [28]. While oppositional defiant disorder and conduct disorder are the most common disruptive disorders in adolescence, accompanied by substance use disorder, such as alcohol or marijuana abuse/dependence [27], the lifetime prevalence of substance abuse/dependence in Korea is as low as $0.25 \%$ [29].
These patterns do not reflect the actual prevalence rates. Some disorders exhibit a repeated cycle of improvement and exacerbation, such as tic disorder, but the reason for the changes in the diagnostic rate of neurodevelopmental disorders that persist for a prolonged period, such as ASD and $\mathrm{ADHD}$, may be that the symptoms of coexisting mental disorders are the major treatment targets in patients with these disorders as an underlying disorder. Based on such age-specific diagnostic distribution patterns for pediatric mental disorders, relevant experts should understand that the currently manifested symptoms are simply phenotypes and that patients may have a persistent underlying illness [30]. Large-scale longitudinal studies are urgently needed to shed light on the changes of diagnosis in the same group of patients as they age.

This study has a few limitations. First, the limitations of the NHICD should be considered. Patients who received healthcare under $\mathrm{R}$ and $\mathrm{Z}$ codes as opposed to $\mathrm{F}$ code, patients who received treatment with non-reimbursement, patients who received treatment with paramedical specialists, and patients prescribed non-reimbursed medications are excluded from the NHICD. There is also limited information about the specific diagnostic instruments or methods used. Second, per the Personal Information Protection Act, information about patients' socioeconomic factors, such as income and education, and health-related factors, such as smoking and drinking, are not provided to researchers. Subsequent studies should obtain socioeconomic factors with cooperation from government agencies and include them in their analysis. Third, this is a cross-sectional study, not a longitudinal study, so long-term follow-up of patients was not possible. Thus, analyzing the trends of changes in diagnoses of an individual through long-term follow-up cohort studies would enable a more detailed design of intervention services.

Despite these limitations, this study has the following significance: as this study only analyzed data on diagnoses made by psychiatrists from the HIRA data, it reflects the incidence rate of mental disorders among the population aged $<19$ years in the clinical setting in Korea.

\section{CONCLUSION}

In the analysis of the annual trends in the diagnostic prevalence of mental disorders in the population aged $<19$ years, there were no significant changes in the overall diagnostic prevalence rate, but there were some significant changes by sex, age, and psychiatric disorder. The most common diagnoses were hyperactivity disorder in male and depressive episode in female. The prevalence of bipolar affective disorder, depressive episode, specific developmental 
disorders of speech and language, pervasive developmental disorder, and tic disorders significantly increased. Four patterns of change were observed in the diagnostic prevalence rates according to age: fortissimo-pianissimo type, crescendo type, accelerando-piano type, and forte-decrescendo type. Follow-up studies are needed to examine how the agespecific patterns for each disorder continue onto early adulthood.

\section{Supplementary Materials}

The online-only Data Supplement is available with this article at https://doi.org/10.5765/jkacap.200017.

\section{Acknowledgments}

This work was supported by the Korea Mental Health R \& D Project, Republic of Korea (No. HM15C1084), and by the Korea Health Technology R\&D Project, Ministry of Health \& Welfare, Republic of Korea (No. HI12C0021/A120029).

The contents including tables and figures in this article are part of Seung Yup Lee's PhD's thesis submitted to the Kyung Hee University School of Medicine in February 2019.

\section{Conflicts of Interest}

The authors have no potential conflicts of interest to disclose.

\section{Author Contributions}

Conceptualization: Geon Ho Bahn. Data curation: Seung Yup Lee. Investigation: Geon Ho Bahn, Seung Yup Lee. Methodology: Geon Ho Bahn. Writing statistics: Seung Yup Lee. Writing_original draft: Seung Yup Lee. Writing—review and editing: Geon Ho Bahn.

\section{ORCID iDs}

Geon Ho Bahn https://orcid.org/0000-0002-3550-0422

Seung Yup Lee https://orcid.org/0000-0003-4120-5603

\section{REFERENCES}

1) Rutter M, Kim-Cohen J, Maughan B. Continuities and discontinuities in psychopathology between childhood and adult life. J Child Psychol Psychiatry 2006;47:276-295.

2) Mesman J, Bongers IL, Koot HM. Preschool developmental pathways to preadolescent internalizing and externalizing problems. J Child Psychol Psychiatry 2001;42:679-689.

3) Costello EJ, Mustillo S, Erkanli A, Keeler G, Angold A. Prevalence and development of psychiatric disorders in childhood and adolescence. Arch Gen Psychiatry 2003;60:837-844.

4) Zablotsky B, Black LI, Maenner MJ, Schieve LA, Danielson ML, Bitsko RH, et al. Prevalence and trends of developmental disabilities among children in the United States: 2009-2017. Pediatrics 2019;144:e20190811.

5) Steinhausen HC, Metzke CW, Meier M, Kannenberg R. Prevalence of child and adolescent psychiatric disorders: the Zürich Epidemiological Study. Acta Psychiatr Scand 1998;98:262-271.

6) Ford T, Goodman R, Meltzer H. The British Child and Adolescent Mental Health Survey 1999: the prevalence of DSM-IV disorders. J Am Acad Child Adolesc Psychiatry 2003;42:1203-1211.

7) Fleitlich-Bilyk B, Goodman R. Prevalence of child and adolescent psychiatric disorders in southeast Brazil. J Am Acad Child Adolesc Psychiatry 2004;43:727-734.

8) Kim JA, Yoon S, Kim LY, Kim DS. Towards Actualizing the Value Potential of Korea Health Insurance Review and Assessment (HIRA) data as a resource for health research: strengths, limita- tions, applications, and strategies for optimal use of HIRA data. J Korean Med Sci 2017;32:718-728.

9) Hong M, Lee SY, Han J, Park JC, Lee YJ, Hwangbo R, et al. Prescription trends of psychotropics in children and adolescents with autism based on nationwide health insurance data. J Korean Med Sci 2017;32:1687-1693.

10) Statistics Korea. Korean Standard Classification of Diseases [cited 2020 March 1]. Available from URL: http://kssc.kostat.go.kr/ksscNew_web/index.jsp\#.

11) World Health Organization. The ICD-10 classification of mental and behavioural disorders: clinical descriptions and diagnostic guidelines. Geneva: World Health Organization;1992.

12) Hwangbo R, Chang H, Hong M, Cho S, Bahn GH. The diagnostic distribution of psychiatric disorders among the population under 19 years old: based on the national insurance data. J Korean Acad Child Adolesc Psychiatry 2016;27:139-145.

13) Singh I. Stimulants: not just naughty, 50 years of stimulant drug advertising. In: Tone A, Watkins ES, editors. Medicating modern America: prescription drugs in history. New York, NY: New York University Press;2007. p.131-155.

14) Huang CL, Wang JJ, Ho CH. Trends in incidence rates of diagnosed attention-deficit/hyperactivity disorder (ADHD) over 12 years in Taiwan: a nationwide population-based study. Psychiatry Res 2020;284:112792.

15) Hong M, Kim B, Hwang JW, Bhang SY, Choi HY, Oh IH, et al. Naturalistic pharmacotherapy compliance among pediatric patients with attention deficit/hyperactivity disorder: a study based on three-year nationwide data. J Korean Med Sci 2016;31:611-616.

16) Hong M, Lee SM, Park S, Yoon SJ, Kim YE, Oh IH. Prevalence and economic burden of autism spectrum disorder in South Korea using national health insurance data from 2008 to 2015. J Autism Dev Disord 2020;50:333-339.

17) Kim J, Kim T, Lee J, Jung K. A study on use status and subsidy appropriateness of developmental rehabilitation service in speechlanguage therapy for disabled children: parental survey. Commun Sci Disord 2018;23:1127-1145.

18) Yoo HI, Cho SC, Kim BN, Kim SY, Shin MS, Hong KE. Psychiatric morbidity of second and third grade primary school children in Korea. Child Psychiatry Hum Dev 2005;36:215-225.

19) Hwangbo R, Chang H, Bahn GH. Diagnostic distribution of psychiatric disorders among Korean young adults. J Korean Acad Child Adolesc Psychiatry 2020;31:80-87.

20) Chen YL, Chen WJ, Lin KC, Shen LJ, Gau SS. Prevalence of DSM5 mental disorders in a nationally representative sample of children in Taiwan: methodology and main findings. Epidemiol Psychiatr Sci 2019;29:e15.

21) Breton JJ, Bergeron L, Valla JP, Berthiaume C, Gaudet N, Lambert J, et al. Quebec Child Mental Health Survey: prevalence of DSM-III-R mental health disorders. J Child Psychol Psychiatry 1999;40:375-384.

22) Cho SJ, Jeon HJ, Kim MJ, Kim JK, Kim US, Lyoo IK, et al. Prevalence and correlates of depressive symptoms among the adolescents in an urban area in Korea. J Korean Neuropsychiatr Assoc 2001;40:627-639.

23) Lavigne JV, Lebailly SA, Hopkins J, Gouze KR, Binns HJ. The prevalence of ADHD, ODD, depression, and anxiety in a community sample of 4-year-olds. J Clin Child Adolesc Psychol 2009;38:315-328.

24) Maulik PK, Mascarenhas MN, Mathers CD, Dua T, Saxena S. Prevalence of intellectual disability: a meta-analysis of population-based studies. Res Dev Disabil 2011;32:419-436.

25) Bufferd SJ, Dougherty LR, Carlson GA, Rose S, Klein DN. Psychiatric disorders in preschoolers: continuity from ages 3 to 6 . Am J Psychiatry 2012;169:1157-1164.

26) Lichtenstein P, Cederlöf M, Lundström S, D’Onofrio BM, Anckarsäter $\mathrm{H}$, Larsson $\mathrm{H}$, et al. Associations between conduct prob- 
lems in childhood and adverse outcomes in emerging adulthood: a longitudinal Swedish nationwide twin cohort. J Child Psychol Psychiatry 2020;61:798-806.

27) Roberts RE, Roberts CR, Xing Y. Rates of DSM-IV psychiatric disorders among adolescents in a large metropolitan area. J Psychiatr Res 2007;41:959-967.

28) Roberts RE, Roberts CR, Chan W. One-year incidence of psychiatric disorders and associated risk factors among adolescents in the community. J Child Psychol Psychiatry 2009;50:405-415.
29) Cho MJ, Hahm BJ, Kim JK, Park KK, Chung EK, Suh TW, et al. Korean Epidemiologic Catchment Area (KECA) study for psychiatric disorders: prevalence of specific psychiatric disorders. J Korean Neuropsychiatr Assoc 2004;43:470-480.

30) Bahn GH, Lee YJ, Han JH. Descriptive psychiatry and the development of diagnostic criteria in the history of child psychiatry and phenomenological descriptive psychiatry. J Korean Acad Child Adolesc Psychiatry 2015;26:1-11. 
Supplementary Table 1. Composition of dataset population from 2010 to 2015 under 19 years old

\begin{tabular}{|c|c|c|c|c|c|c|}
\hline Types & 2010 & 2011 & 2012 & 2013 & 2014 & 2015 \\
\hline \multicolumn{7}{|l|}{ General population } \\
\hline Male & $5,692,370$ & $5,551,581$ & $5,420,522$ & $5,268,669$ & $5,118,510$ & $4,986,176$ \\
\hline Female & $5,189,682$ & $5,080,245$ & $4,985,332$ & $4,871,277$ & $4,753,832$ & $4,647,132$ \\
\hline Total & $10,882,052$ & $10,631,826$ & $10,405,854$ & $10,139,946$ & $9,872,342$ & $9,633,308$ \\
\hline \multicolumn{7}{|c|}{ Total population in sample data } \\
\hline Male & 547,487 & 531,825 & 521,121 & 506,634 & 494,865 & 481,900 \\
\hline Female & 500,315 & 488,122 & 480,742 & 469,735 & 460,591 & 450,757 \\
\hline Total & $1,047,802$ & $1,019,947$ & $1,001,863$ & 976,369 & 955,456 & 932,657 \\
\hline \multicolumn{7}{|l|}{ Medical insurance } \\
\hline Male & 529,666 & 515,661 & 506,766 & 493,496 & 483,097 & 471,003 \\
\hline Female & 483,094 & 472,571 & 466,926 & 457,263 & 449,117 & 440,264 \\
\hline Subtotal & $1,012,760$ & 988,232 & 973,692 & 950,759 & 932,214 & 911,267 \\
\hline \multicolumn{7}{|l|}{ Medical aid } \\
\hline Male & 17,821 & 16,164 & 14,355 & 13,138 & 11,768 & 10,897 \\
\hline Female & 17,221 & 15,551 & 13,816 & 12,472 & 11,474 & 10,493 \\
\hline Subtotal & 35,042 & 31,715 & 28,171 & 25,610 & 23,242 & 21,390 \\
\hline
\end{tabular}


Supplementary Table 2. Number of population under 19 years diagnosed with psychiatric disorders according to age and years during 2010-2015

\begin{tabular}{|c|c|c|c|c|c|c|}
\hline Type & 2010 & 2011 & 2012 & 2013 & 2014 & 2015 \\
\hline \multicolumn{7}{|l|}{ General population } \\
\hline Male & $5,692,370$ & $5,551,581$ & $5,420,522$ & $5,268,669$ & $5,118,510$ & $4,986,176$ \\
\hline Female & $5,189,682$ & $5,080,245$ & $4,985,332$ & $4,871,277$ & $4,753,832$ & $4,647,132$ \\
\hline Total & $10,882,052$ & $10,631,826$ & $10,405,854$ & $10,139,946$ & $9,872,342$ & $9,633,308$ \\
\hline \multicolumn{7}{|c|}{ Population with psychiatric disorders } \\
\hline Male & 14,449 & 14,755 & 15,362 & 14,024 & 12,601 & 11,680 \\
\hline Female & 8,963 & 8,675 & 9,403 & 8,245 & 7,602 & 7,141 \\
\hline Total & 23,412 & 23,430 & 24,765 & 22,269 & 20,203 & 18,821 \\
\hline \multicolumn{7}{|l|}{ Medical insurance } \\
\hline Male & 13,447 & 13,786 & 14,356 & 13,107 & 11,711 & 10,812 \\
\hline Female & 8,078 & 7,858 & 8,590 & 7,534 & 6,907 & 6,483 \\
\hline Subtotal & 21,525 & 21,644 & 22,946 & 20,641 & 18,618 & 17,295 \\
\hline \multicolumn{7}{|l|}{ Medical aid } \\
\hline Male & 1,002 & 969 & 1,006 & 917 & 890 & 868 \\
\hline Female & 885 & 817 & 813 & 711 & 695 & 658 \\
\hline Subtotal & 1,887 & 1,786 & 1,819 & 1,628 & 1,585 & 1,526 \\
\hline \multicolumn{7}{|l|}{$0-3$ years } \\
\hline Male & 603 & 683 & 598 & 605 & 577 & 482 \\
\hline Female & 334 & 354 & 301 & 271 & 257 & 235 \\
\hline Subtotal & 937 & 1,037 & 899 & 876 & 834 & 717 \\
\hline \multicolumn{7}{|l|}{$4-6$ years } \\
\hline Male & 1,384 & 1,401 & 1,391 & 1,390 & 1,265 & 1,262 \\
\hline Female & 702 & 689 & 679 & 608 & 526 & 511 \\
\hline Subtotal & 2,086 & 2,090 & 2,070 & 1,998 & 1,791 & 1,773 \\
\hline \multicolumn{7}{|l|}{$7-9$ years } \\
\hline Male & 2,783 & 2,697 & 2,800 & 2,411 & 2,141 & 2,038 \\
\hline Female & 1,146 & 1,043 & 1,002 & 854 & 783 & 721 \\
\hline Subtotal & 3,929 & 3,740 & 3,802 & 3,265 & 2,924 & 2,759 \\
\hline \multicolumn{7}{|l|}{$10-12$ years } \\
\hline Male & 3,110 & 3,153 & 3,168 & 2,699 & 2,328 & 2,152 \\
\hline Female & 1,269 & 1,256 & 1,346 & 1,057 & 939 & 864 \\
\hline Subtotal & 4,379 & 4,409 & 4,514 & 3,756 & 3,267 & 3,016 \\
\hline \multicolumn{7}{|l|}{$13-15$ years } \\
\hline Male & 3,280 & 3,366 & 3,642 & 3,330 & 2,933 & 2,429 \\
\hline Female & 2,266 & 2,107 & 2,473 & 2,101 & 1,876 & 1,700 \\
\hline Subtotal & 5,546 & 5,473 & 6,115 & 5,431 & 4,809 & 4,129 \\
\hline \multicolumn{7}{|l|}{$16-18$ years } \\
\hline Male & 3,289 & 3,455 & 3,763 & 3,589 & 3,357 & 3,317 \\
\hline Female & 3,246 & 3,226 & 3,602 & 3,354 & 3,221 & 3,110 \\
\hline Subtotal & 6,535 & 6,681 & 7,365 & 6,943 & 6,578 & 6,427 \\
\hline
\end{tabular}


Supplementary Table 3. Composition of dataset for each psychiatric disorder

\begin{tabular}{|c|c|c|c|c|c|c|c|c|c|c|c|c|}
\hline \multirow{2}{*}{ F-code } & \multicolumn{6}{|c|}{ Male } & \multicolumn{6}{|c|}{ Female } \\
\hline & 2010 & 2011 & 2012 & 2013 & 2014 & 2015 & 2010 & 2011 & 2012 & 2013 & 2014 & 2015 \\
\hline F31 & 374 & 448 & 702 & 718 & 831 & 873 & 229 & 261 & 450 & 438 & 423 & 507 \\
\hline F32 & 2,148 & 2,122 & 2,678 & 2,523 & 2,164 & 2,260 & 1,810 & 1,770 & 2,362 & 2,033 & 1,877 & 1,837 \\
\hline F41 & 1,872 & 2,152 & 2,705 & 2,594 & 2,260 & 2,119 & 1,779 & 1,834 & 2,235 & 2,155 & 1,978 & 1,964 \\
\hline F43 & 1,052 & 1,087 & 1,174 & 907 & 910 & 753 & 1,104 & 1,039 & 1,178 & 939 & 927 & 753 \\
\hline F45 & 796 & 718 & 730 & 761 & 613 & 532 & 918 & 877 & 922 & 859 & 768 & 744 \\
\hline F48 & 430 & 447 & 419 & 380 & 350 & 306 & 512 & 510 & 529 & 474 & 476 & 379 \\
\hline F70 & 715 & 741 & 780 & 651 & 568 & 626 & 340 & 352 & 345 & 296 & 295 & 267 \\
\hline F80 & 908 & 966 & 965 & 1,044 & 981 & 950 & 264 & 287 & 281 & 314 & 302 & 310 \\
\hline F84 & 948 & 1,074 & 1,077 & 1,106 & 1,132 & 1,174 & 188 & 218 & 216 & 246 & 244 & 263 \\
\hline F90 & 6,525 & 6,815 & 7,289 & 6,495 & 5,706 & 5,301 & 1,797 & 1,823 & 2,016 & 1,734 & 1,564 & 1,531 \\
\hline F91 & 685 & 697 & 888 & 818 & 737 & 745 & 250 & 213 & 285 & 233 & 218 & 219 \\
\hline F93 & 1,209 & 1,427 & 1,461 & 1,235 & 1,017 & 925 & 746 & 771 & 816 & 617 & 499 & 473 \\
\hline F95 & 1,723 & 1,739 & 2,013 & 1,892 & 1,826 & 1,589 & 351 & 391 & 416 & 395 & 375 & 391 \\
\hline F98 & 817 & 873 & 899 & 767 & 672 & 569 & 472 & 458 & 474 & 387 & 325 & 302 \\
\hline Other & 4,368 & 4,321 & 4,591 & 4,183 & 3,773 & 3,781 & 2,914 & 2,733 & 3,092 & 2,711 & 2,647 & 2,547 \\
\hline
\end{tabular}

F31=bipolar affective disorder, F32=depressive episode, F41=other anxiety disorders, F43=reaction to severe stress, and adjustment disorders, F45=somatoform disorders, F48=other neurotic disorders, F70=mild mental retardation, F80=specific developmental disorders of speech and language, F84=pervasive developmental disorders, F90=hyperkinetic disorders, F91=conduct disorders, F93=emotional disorders with onset specific to childhood, F95=tic disorders, F98=other behavioural and emotional disorders with onset usually occurring in childhood and adolescence 